\title{
Compliance of Lebanese Pickling Industry with Lebanese and International Standards
}

\author{
Sami Tlais ${ }^{1, a, *}$, Hayat Omairi ${ }^{2, b}$, Ali Al Khatib ${ }^{2, c}$, Hassan HajjHussein ${ }^{3, d}$ \\ ${ }^{1}$ Biological and Chemical Department, Lebanese International University, Bekaa/Rayak, Lebanon. \\ ${ }^{2}$ Nutrition and Food Science Department, Lebanese International University, Beirut/Bekaa, Lebanon. \\ ${ }^{3}$ Biological and Chemical Department, Lebanese International University, Rayak, Lebanon. \\ *Corresponding author
}

\begin{tabular}{l|l}
\hline A R T I C L E I N F O & A B S T R A C T \\
\hline $\begin{array}{l}\text { Research Article } \\
\text { Received : 30/03/2020 } \\
\text { Accepted : 19/06/2020 }\end{array}$ & $\begin{array}{l}\text { In light of recent news reporting the use of banned colorants in Lebanese-made pickled turnips } \\
\text { exported to the European Union (EU) by the Rapid Alert System of Food and Feed (RASFF), The } \\
\text { Lebanese Consumer Protection Association tested samples of pickled turnips being sold to the } \\
\text { public and confirmed the use of rhodamine B. Many products were pulled off the market and were } \\
\text { replaced with new products that were supposed to be free of any banned colorants. We selected 5 } \\
\text { different brands of pickled turnips and tested them for pH, salinity, nitrites, and colorants. We tested } \\
\text { the salinity using two methods: evaporation and titration. The concentration of nitrites was tested } \\
\text { by absorbency method. The presence of colorants was determined using TLC and absorbency } \\
\text { method. We determined that the newly released pickled turnips comply with the rules and } \\
\text { regulations adopted by the Lebanese Standards Institution (LIBNOR) and the international } \\
\text { standards according to the Codex Alimentarius. }\end{array}$ \\
$\begin{array}{l}\text { Keywords: } \\
\text { Fermented turnips }\end{array}$
\end{tabular}

Pickled turnips

Banned colorants

Lebanon

Pickled-turnips

\section{Introduction}

The pickled vegetable industry is a major source of income for many Lebanese families and is one of the top homemade food industries in Lebanon. At the industrial level, there are around 76 registered factories that produce pickles in Lebanon (ALI, 2019). The total annual production for Lebanese pickled vegetables amounts to \$27 million dollars, \$17 million of which comes from exports, which makes the pickling industry an important source of foreign revenue. According to a study done by USAID, Lebanese pickle exports have increased by $49 \%$ between the years 2009 and 2012 (USAID, 2014).

Out of the many pickled vegetables essential to Lebanese cuisine, turnips are among the most popular due to their vibrant color, crunch, and sour taste. Pickled turnips are widely used as garnish in many traditional Lebanese sandwiches and platers (e.g. Falafel, Fool (fava beans), and Hummus). Turnips have several health benefits that have been studied and recorded over the years. One of the oldest known benefits of turnip, and especially turnip juice, is supplying peptic ulcer patients with much needed vitamin C (Picton, 1940). Turnips are also beneficial in reducing the risk of cardiovascular diseases (Zhang et al., 2011), and it was shown that glucosinolates from turnip roots are capable of stimulating bone formation (Jeong et al., 2015).

Turnips are typically planted in the spring or late spring, which limits the availability of fresh turnips to only a few months per year. Due to their nutritional benefits, turnip fermentation became one of the oldest adopted solutions to make turnips available all year round. Pickled turnips, similar to fresh turnips, are a good source of calcium, potassium, and vitamin C (Altay et al., 2013).

Traditionally, homemade Lebanese pickled turnips are prepared by adding sliced turnips to a glass jar, warm brine, vinegar, few slices of beets for coloring, and then tightly sealing the jar to keep air out for the fermentation process to take place. They are typically allowed to ferment from one week to one month depending on the desired level of acidity. The shelf life is commonly associated with the color of the pickles, which starts as pinkish-red, due to 
added beets, and gradually becomes colorless with time as the colorant breaks down. The beets/colorant do not extend the life of the turnip; however, it simply acts as a timeindicator/freshness-indicator since the color of the beets fades with time (Omairi, 2020).

Red beets contain betanin, a natural colorant that is authorized by the EU for use as a food colorant. This pigment is given the E number (E162). According to the Joint FAO/WHO Expert Committee on Food Additives (JECFA), beetroot red comes as red or dark red liquid, paste, or powder (JECFA, 2007). Beetroot color has long been consumed as a natural dietary constituent. It has been used in different food products such as sugar candy, yogurt, ice cream, salad dressing, cake mix, powdered drinks, soft drinks, and gelatin (EFSA, 2015). However, the food industry has become less reliant on betanin due to its low stability, a fact that has seen many food industries make the switch to using banned colorants of higher stability such as rhodamine B. (Imtyaj Khan, 2016)

Unfortunately, Lebanese pickled turnips were recently found to be non-compliant with Lebanese standards set by the Lebanese Standardization Institute (LIBNOR) and international standards for food safety, mainly due to the use of rhodamine $\mathrm{B}$, which resulted in halting the export of pickled turnips to Europe (RASSF, 2018). The Lebanese Consumer Protection Association also discovered the use of banned dyes in pickled turnips that were being sold to the Lebanese public, which resulted in a major recall of pickled turnips from supermarket shelves. New batches of pickled turnips were released to the market, supposedly fully compliant with the international and LIBNOR standards (An Nahar, 2018). In this study, we looked into 5 of the top selling brands of pickled turnips currently available on the Lebanese market. We focused on whether they contain artificial colorants like rhodamine B, or not. In addition, we compared their $\mathrm{pH}$, salinity, and nitrite levels to determine if they are all in accordance with international and LIBNOR standards.

\section{Materials and Methods}

\section{Samples}

Jars of pickled turnips from five of the top selling brands in Lebanon were purchased from the local supermarkets during October 2018. Four of the five were made in Lebanon and one was made in Syria. The five brands were chemically analyzed for $\mathrm{pH}$, salinity, nitrites content, and content of banned colorants.

\section{Determination of $\mathrm{pH}$}

The $\mathrm{pH}$ of the samples was measured by $\mathrm{pH}$ meter $\left(\right.$ Edge $\left.{ }^{\circledR}\right)$. The test was performed in triplicates.

\section{Determination of Salt by Evaporation Method (Total Soluble Solids)}

A sample of $60 \mathrm{~mL}$ of the filtered pickle solution was added to a pre weighted $100 \mathrm{~mL}$ beaker. The beaker was heated on a hotplate until all fluids have completely evaporated. The beaker was then further dried in the oven overnight at $110^{\circ} \mathrm{C}$ to ensure total liquid evaporation. Each test was done in triplicates.

\section{Determination of Salt by Titration Method}

The solution from each sample was diluted 100-times, transferred to an Erlenmeyer flask and neutralized by titration with $0.1 \mathrm{M}$ sodium hydroxide using phenolphthalein as an indicator. The neutralized sample was transferred to a $250 \mathrm{ml}$ volumetric flask, shaken and filtered. The filtrate was titrated with $0.1 \mathrm{M}$ silver nitrate using $1 \mathrm{ml}$ of $5 \%$ potassium chromate solution as an indicator. The volume of silver nitrate required to produce reddish brown end point is recorded (Karl et al., 2002). The test is repeated three times for each sample.

\section{Determination of Nitrites}

Pickled turnips (5grams) were crushed, deproteinated and defatted with precipitation with $10.0 \mathrm{ml} \mathrm{ZnSO}_{4}$ $(0.42 \mathrm{~mol} / \mathrm{L})$ followed by filtration. $1.0 \mathrm{ml}$ of each color development $(0.2 \%$ sulfanilamide, $0.1 \% \mathrm{~N}$-(1-napthyl)ethylenediamine, and $44.5 \% \mathrm{HCl}$ ) reagent was added sequentially to the filtrate. Then the absorbance was measured at $538 \mathrm{~nm}$ against pickled solution as blank. The concentration of the nitrite was determined by using standardization curve from 5 to $30 \mathrm{mg} / \mathrm{kg}$ of nitrite. Absorbance was measured on Optizen POP spectrophotometer (Cai Hou et al., 2013). The nitrite analysis was repeated 3 times for each pickle sample.

\section{Measurement of Peak Color Wavelength}

The color intensity of each sample was determined by measuring the absorbance at the maximum wavelength on Optizen POP spectrophotometer. The range of wavelengths was taken between 200 to $700 \mathrm{~nm}$ at intervals of $5 \mathrm{~nm}$.

\section{Detection of Banned Colorants}

Solutions of turnips and references were applied to chromatographic plates, as bands, by means of a CAMAG Automatic TLC Sampler (CAMAG, Muttenz, Switzerland) and developed in horizontal DS chambers. The locations of the bands were determined under UV light $(\lambda=365 \mathrm{~nm})$. Methanol was used as elution solvent. Results were visualized with the use of CAMAG TLC Visualizer and quantified with densitometer CAMAG TLC Scanner equipped with Wincats software under UV light $(\lambda=560$ $\mathrm{nm})$ for azorubine. The azorubine concentration was calculated based on a standardization curve for azorubine (Morlock and Oellig, 2009).

\section{Data and Figures}

Statistical analysis and figures were prepared using Graphpad Prism 8.3.0.

\section{Results and Discussion}

According to LIBNOR, the acidity of pickles should range between $2 \%$ and $4 \%$ and according to the international Codex, the $\mathrm{pH}$ should be lower than 4.6 (Codex Alimentarius, 2007). Acidic medium usually inhibits spoilage bacterial growth, so low $\mathrm{pH}$ is used frequently for food preservation such as pickling. Our results showed that the measured $\mathrm{pH}$ values of the collected pickled were $3.6 \pm$ 0.02 for brand $1,3.3 \pm 0.01$ for brand $2,3.2 \pm 0.03$ for brand $3,3.1 \pm 0.05$ for brand 4 , and $3.2 \pm 0.01$ for brand 5 . The assessment of $\mathrm{pH}$ values of the five different pickled turnip products showed that all five samples were within the 
acceptable range (Figure 1). In our assessment of the five different pickled turnip products, we determined all five to be within the acceptable range (Figure 1).

According to the Codex Alimentarius, the $\mathrm{pH}$ for pickled vegetables must not be above 4.6. The dotted line represents the 4.6 mark set forth by the internationally adopted standards for pickled vegetables. As is evident from the figure, all tested samples were within the allowed $\mathrm{pH}$ range. We were not interested in testing whether the $\mathrm{pH}$ level was significantly different among the five brands, we were merely interested in checking if the brands were compliant with the standards adopted by LIBNOR and the international community. All values are mean \pm standard error of mean (SEM) of five different brands, each experiment was replicated $n=3$.

Salt highly affects the fermentation process. Salt serves four major roles: it influences the type and extent of microbial activity, helps to prevent the softening of the vegetable tissue, contributes to the flavor of the final product, and aids in the rupturing of membranes which allows the diffusion of sugars used by microbes for growth and metabolic activities (Perez-Diaz, 2013). According to LIBNOR standards, the amount of salt used in pickled vegetables must not exceed $12 \%$ of the gross weight; in addition, the international codex states that salt sour pickles must have a salt $(\mathrm{NaCl})$ concentration that ranges between 5 and $10 \%$. In this assessment, salt concentration was determined by two methods: evaporation (Figure 2) and titration (Figure 3). In both methods, we determined that all samples were compliant with the standards set forth by LIBNOR. Using the evaporation method (Figure 2), the results of salt content were $6.8 \% \pm 0.4$ for brand $1,10.0 \%$ \pm 0.5 for brand $2,4.6 \% \pm 0.1$ for brand $3,5.9 \% \pm 0.7$ for brand 4 , and $6.8 \% \pm 0.3$ for brand 5 . The results of the titration method (Figure 3 ), which is more accurate method to test $\mathrm{NaCl}$ content, showed that the salt content of brand 1 was $5.6 \% \pm 0.1$, brand 2 was $5.6 \% \pm 0.2$, brand 3 was $4.6 \% \pm 0.3$, brand 4 was $3.8 \% \pm 0.2$, and brand was $54.8 \%$ \pm 0.2 .

The dotted line at $12 \%$ represents the maximum allowed concentration as per the LIBNOR adopted standards. It is evident that all tested brands were well below the limit. We were not interested in testing whether the salt level was significantly different among the five brands, we were merely interested in checking if the brands were compliant with the standards adopted by LIBNOR and the international community. All values are mean \pm SEM of five different brands, each experiment was replicated $n=3$.

The titration method is far more accurate than the evaporation method in determining the actual content of $\mathrm{NaCl}$. The dotted line at $12 \%$ represents the maximum allowed concentration as per the LIBNOR adopted standards. As is evident from the figure, all tested brands were below the allowed maximum of $12 \%$ per weight set forth by LIBNOR. We were not interested in testing whether the salt level was significantly different among the five brands, we were merely interested in checking if the brands were compliant with the standards adopted by LIBNOR and the international community. Data

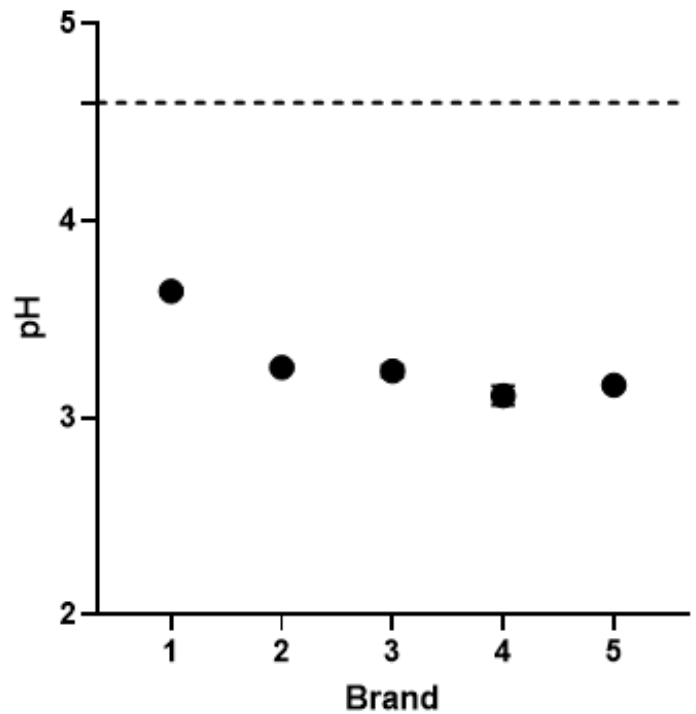

Figure 1. pH measurement of all five brands

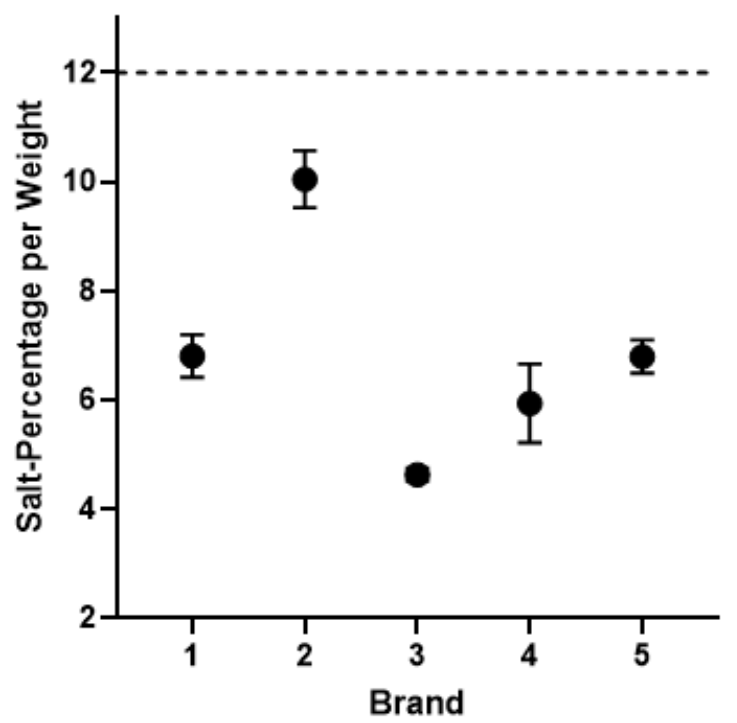

Figure 2. Salt content determined as percentage of the total weight by evaporation method

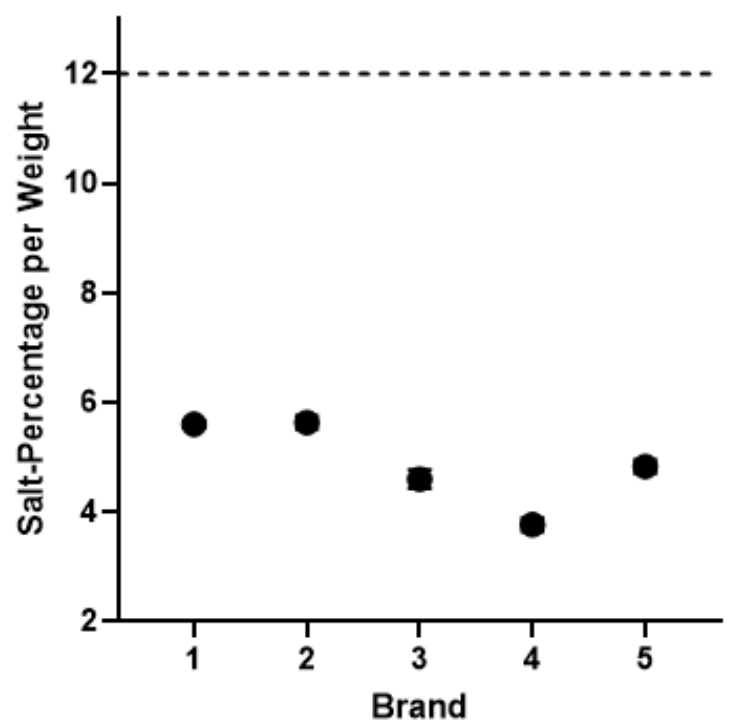

Figure 3. Salt content determined as percentage of the total weight by titration method 


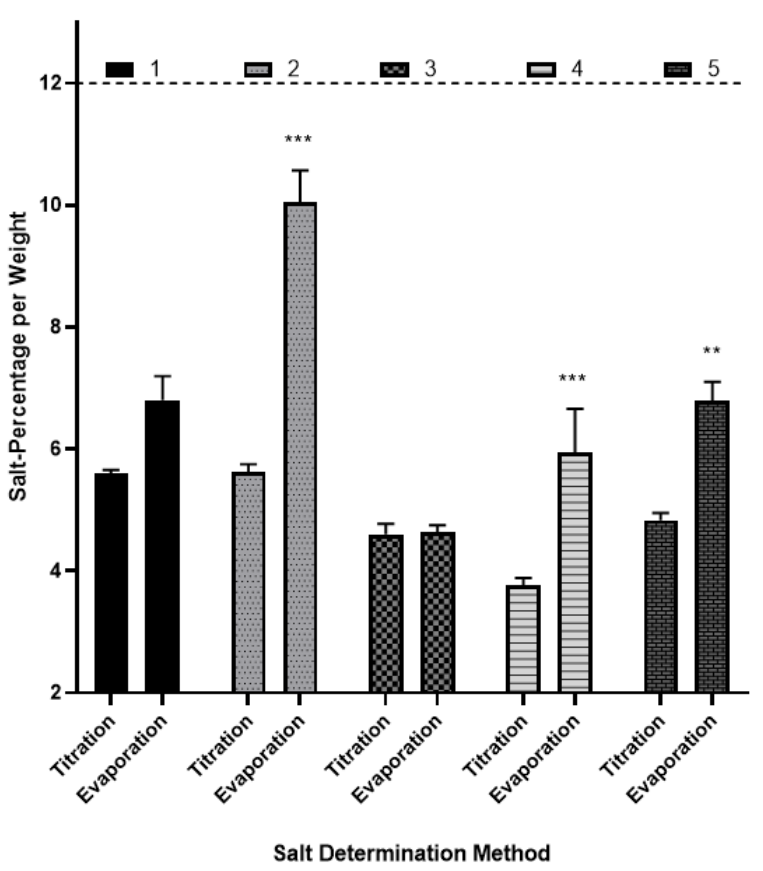

Figure 4. Comparison between the two different salt content determination methods

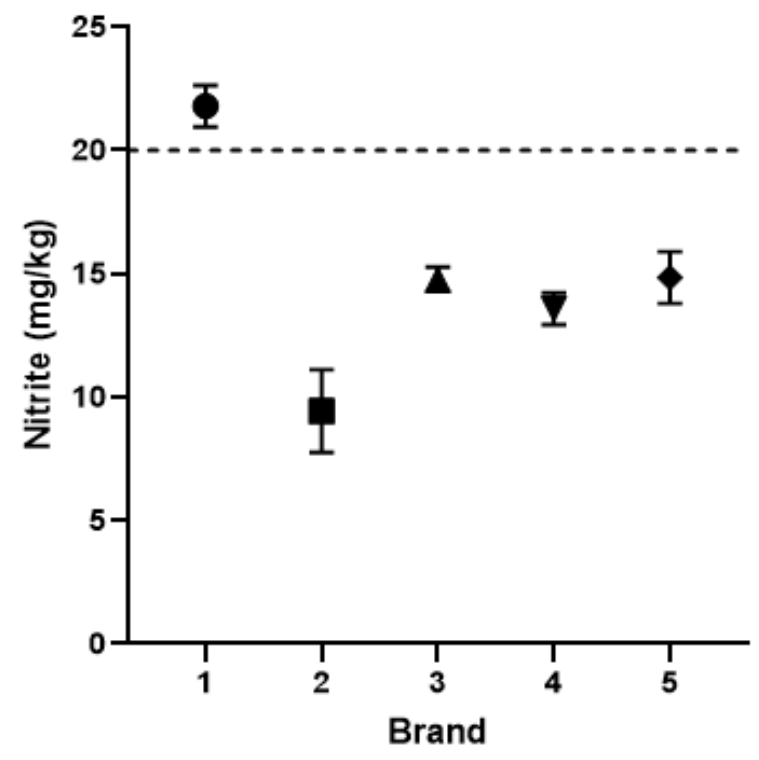

Figure 5. Nitrite content determined as $\mathrm{mg} / \mathrm{kg}$ of the sample

We performed a comparison for each brand between the salt content determined through the titration method and the salt content determined through the evaporation method. Any detected difference would be due to additional solutes other than table salt that are added to the pickles. Such additives could serve to enhance the color, flavor, and texture. Among the five tested brands, we detected significant difference between the measurements of brand 2 , 4 , and 5 (Figure 4). The dotted line at $12 \%$ represents the maximum allowed concentration as per the LIBNOR adopted standards. For each brand, we compared the salt content determined by the two methods and reported any statistical significance using two-way ANOVA Sidak's multiple comparisons test. Data represent mean \pm SEM of five different brands, each experiment was replicated $n=3$. We determined that there was no difference in the salt measurement of Brand 1 between the two adopted methods. $* * \mathrm{P}<0.01$ and $* * * \mathrm{P}<0.001$.

The World Health Organization (WHO) listed pickled vegetables as possible carcinogens due to the presence of nitrites. The WHO also regulated the limit for maximum nitrite levels in pickled vegetables as $20 \mathrm{mg} / \mathrm{kg}$, and the acceptable daily intake (ADI) for nitrite ion as $0.06 \mathrm{mg} / \mathrm{kg}$ body weight (EFSA, 2017). For this reason, the measurement of nitrite content in pickled vegetables is an important part of the assessment especially for food safety issues. The nitrite levels varied between the tested samples. The mean nitrite level for brand 1 was $(21.79 \mathrm{mg} / \mathrm{kg} \pm$ $0.48)$, brand $2(9.43 \mathrm{mg} / \mathrm{kg} \pm 0.97)$, brand $3(14.78 \mathrm{mg} / \mathrm{kg} \pm$ $0.28)$, brand $4(13.58 \mathrm{mg} / \mathrm{kg} \pm 0.37)$, and brand 5 $(14.85 \mathrm{mg} / \mathrm{kg} \pm 0.60)$. All values were within the acceptable range set by WHO (Figure 5). According to the Codex Alimentarius, the maximum allowed nitrite content for pickled vegetables is $20 \mathrm{mg} / \mathrm{kg}$. As is evident from the figure, 4 of the 5 tested brands were well below the allowed limit, however, brand 1 was slightly above that limit; however, it was found to be non-significant based on a Tukey's multiple comparison test. We were not interested in testing whether the salt level was significantly different among the five brands, we were merely interested in checking if the brands were compliant with the standards adopted by LIBNOR and the international community. All values are mean \pm standard deviation of five difference brands, each experiment was replicated $n=3$.

Beets are added to pickled turnip jars to give them their traditional pinkish red color. The active coloring agent in natural beets is betanin. Betanin is approved for the use as food colorant according to FDA, OJEU, and LIBNOR (FDA, 2015; OJEU, 2012; LIBNOR, 2000). The resulting color from adding beets or betanin is not very stable and deteriorates over time, which is why people have traditionally come to associate the color intensity of the product with its freshness (Imtyaj Khan, 2016). For this reason, some companies switched to using more stable food colorants to improve the look of the product and influence consumer judgement as to the freshness of the product. Some Lebanese brands were found to contain the banned colorant rhodamine B (An Nahar, 2018). To ensure the safety of the products and their compliance with standards about food colorants, all the five brands were tested for the content in most widely used four banned pinkish red colorants in the industry: allura red, rhodamine $\mathrm{B}$, ponceau, and azorubine. Using thin layer chromatography, only one band for azorubine was detected in brand 5. Spectrophotometry was also used to detect the peak absorbance at a wide range of wavelengths $(\lambda)$. The data from the spectrophotometry analysis revealed a maximum absorbance at $535 \mathrm{~nm}$ for brands 1 through 4 , which matches the wavelength of the natural betanin dye. However, brand 5 had maximum absorbance at 560nm, which matches the wavelength of azorubine. Azorubine is approved for use by LIBNOR and EU (EFSA, 2009) but not by the FDA. The level detected in the sample $(0.012 \mathrm{mg} / \mathrm{kg})$ was lower than the permitted level of use (50 $\mathrm{mg} / \mathrm{kg}$; Table 1). The calculated level of colorant was determined using a standardization curve of absorbance using CAMAG TLC scanner. 
Table 1. Detection of colorant in pickled turnips using spectrophotometry $(\mathrm{mg} / \mathrm{kg})$

\begin{tabular}{l|lllll}
\hline Colorant & Brand 1 & Brand 2 & Brand 3 & Brand 4 & Brand 5 \\
\hline Allura Red & 0.0 & 0.0 & 0.0 & 0.0 & 0.0 \\
Rhodamine B & 0.0 & 0.0 & 0.0 & 0.0 & 0.0 \\
Ponceau & 0.0 & 0.0 & 0.0 & 0.0 & 0.0 \\
Azorubine & 0.0 & 0.0 & 0.0 & 0.0 & 0.012 \\
\hline
\end{tabular}

\section{Conclusion}

In light of recent findings which revealed the use of banned colorants in the Lebanese pickling industry, the Lebanese Consumer Protection Association cracked down on the food industry in Lebanon and forced implicated brands to pull their products off the market and replace them with new ones that comply with the Lebanese standards (LIBNOR) and the international standards (Codex Alimentarius). We studied the compliance of the Lebanese pickling industry by investigating 5 of the most commonly sold brands of turnip pickles on the Lebanese market. Our investigation confirmed that the new products available on the market were in full compliance with the international standards in terms of the use of food colorant, $\mathrm{pH}$ level, salt content, and nitrites.

The results of our investigation are a positive testament to the compliance of the Lebanese pickling industry with Lebanese and International standards and are a clear indicator that the Lebanese consumer can trust to buy pickled turnips currently available on the market.

\section{References}

Altay F, Karbancioglu-Guler F, Daskaya-Dikmen C, Heperken D. 2013. A review on traditional Turkish fermented nonalcoholic beverages: Mirobiota, fermentation process and quality characteristics. International Journal of Food Microbiology, 167: 44-56

An Nahar. 2018. Pickled Turnip analysis result. An Nahar newspaper, Nov 14, 2018 [accessed data on April 2019]: https://www.annahar.com/article/898570

Cai Hou J, Jiang C, Long Z. 2013. Nitrite level of pickled vegetables in northeast China. Food Control, 29: 7-10

EFSA. 2009. Panel on Food Additives and Nutrient Sources added to Food (ANS), 2009, Scientific Opinion on the reevaluation of Azorubine/Carmoisine (E 122) as a food additive on request the European Commission. EFSA Journal, 7(11), 1332. doi:10.2903/j.efsa.2009.1332.

EFSA. 2015. ANS Panel (EFSA Panel on Food Additives and Nutrient Sources added to Food), 2015, Scientific Opinion on the re-evaluation of beetroot red (E 162) as a food additive. EFSA Journal, 13(12), 4318. doi:10.2903/j.efsa.2015. 4318ALI. 2019. Association of Lebanese Industrialists (2019). The Directory of Exports and Industrial Firms in Lebanon; https://www.lebanon-industry.com/home [accessed date: March 6, 2020]
EFSA. 2017. ANS Panel (EFSA Panel on Food Additives and Nutrient Sources added to Food), 2017. Scientific Opinion on the re-evaluation of potassium nitrite (E 249) and sodium nitrite (E 250) as food additives. EFSA Journal, 15(6), 4786, 157 pp. https://doi.org/10.2903/ j.efsa.2017.4786

FAO/WHO. 2007. Joint Codex Alimentarius Commission. Standard for pickled fruits and vegetables. Codex Stan, 2602007.

FDA. 2015. Color Additive Status List, https://www.fda.gov/ industry/color-additive-inventories/color-additive-status-list [accessed date: March 6, 2020]

Food color additives banned in the USA, Association of Food and Drug Officials. Available from: http://importedfoods.afdo.org [Accessed March 6, 2020]

Imtyaj Khan M. 2016. Stabilization of Betalains: A Review. Food Chemistry, 197: 1280-1285

JECFA. 1987. Beet Red, http://www.fao.org [accessed date: March 6, 2020]

Jeong J, Park H, Hyun H, Kim J, Kim H, Oh HI, Hwang HS, Kism DK, Kim HH. 2015. Effects of glucosinolates from turnip (Brassica rapa L) root on bone formation by human osteoblast-like MG-63 cells and in normal young rats. Phytother.Res, 29: 902-909

Karl H, Äkesson G, Etienne M, Huidobro A, Luten J, Mendes R, Tejada M, Morlock GE, Oellig C. 2009. Rapid planar chromatographic analysis of 25 water soluble dyes used as food additives. J AOAC Int, 92: 745-756

LIBNOR. 2000. Lebanese Standards Institution, 241

Morlock G, Oellig C. 2009. Rapid planar chromatographic analysis of 25 water-soluble dyes used as food additives. J. AOAC Int. 92(3): 745-756

Oehlenschläger J. 2002. WEFTA Interlaboratory Comparison on Salt Determination in Fishery Products. Journal of Aquatic Food Product Technology 11: 215-228

OJEU. 2012. Official Journal of the European Union, volume 55, L83

Omairi H. 2020. Assessment, preparation and color stability of pickled turnips, Lebanese International University, Thesis [unpublished data]

Perez-Diaz IM, Breidt F, Buescher RW, Arroyo-Lopez FN, Jimenez-Diaz R, Garrido Fernandez A, Bautista Gallego J, Yoon SS, Johanningsmeier SO. 2013. Compendium of Methods for the microbiological examination of foods, Chapter 51, APHA PRESS, ISBN (PDF): 978-0-87553-022-2

Picton LJ. 1940. Turnip juice for pepetic ulcer. British Medical Journal, 1:111

RASSF. 2020. RASSF Portal. Notification details- 2018.2883. Unauthorized color Rhodamine B in pickled turnips from Lebanon. https://webgate.ec.europa.eu [accessed date: March $6,2020]$

USAID. 2014. Processed Food Value Chain Assessment Report II. Lebanon Industry Value Chain Development (LIVCD).

Zhang X, Shu X, Xiang Y, Yang G, Li H, Goa J, Cai H, Goa Y, Zheng W. 2011. Cruciferous vegetable consumption associated with reduced risk of total and cardiovascular disease mortality. American Society for Nutrition, 94: 240-6 